\section{PARENTS NEED HELP IN WAR ON SUGAR}

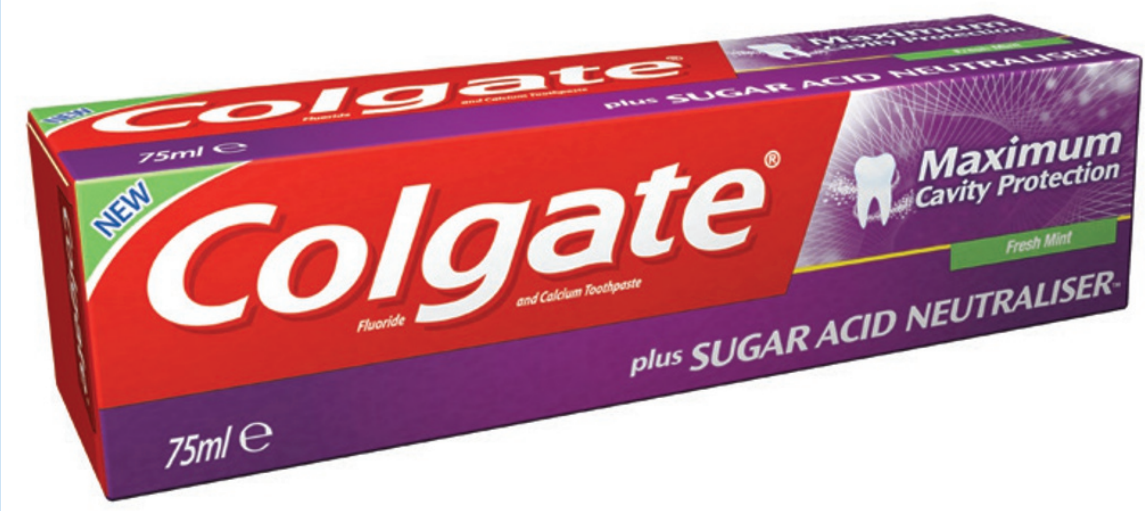

New research from Colgate shows that parents need additional support to help look after their children's teeth. Almost two thirds of dental professionals (DPs) find themselves repeating the same dietary and oral health advice for caries prevention in children during their appointment most or all of the time. DPs also believe that only $1 \%$ of parents always follow the advice given to them about their child's diet.

The survey, commissioned by Colgate as part of the launch for the new Colgate Maximum Cavity Protection plus Sugar Acid Neutraliser toothpaste, gathered insights into the diet and oral health practices of DPs in relation to their own families, and the advice that they give to parents on caries prevention for their children.

A staggering $97 \%$ of DPs see at least one child every day in their practice who is suffering from caries due to a high-sugar diet, with more than a quarter (26\%) saying that they see at least five children.
All DPs know the effect of a high sugar diet on caries, and $92 \%$ of those surveyed mostly or always consider the impact that diet has on their own children's caries when shopping for food. However, three in ten DPs admit to knowing very little about hidden sugars, and $28 \%$ completely agree that it is very difficult to avoid buying foods that do not pose an everyday caries risk as even foods labelled as 'healthy' can contain hidden sugars, including bread, yoghurt breakfast cereal and baked beans.

Colgate Maximum Cavity Protection plus Sugar Acid Neutraliser uses the first and only Sugar Acid Neutraliser technology to directly target acids produced from free sugar in plaque. The technology has been clinically proven to provide greater cavity protection versus regular everyday toothpaste with the same level of fluoride.

www.colgateprofessional.co.uk/ products/MaximumCavityProtection

\section{CHARCOAL FOR WHITE TEETH}

Beverly Hills Formula Perfect White Black toothpaste is formulated with activated charcoal, an ingredient that has been used in oral hygiene for centuries and is proven to whiten teeth and help combat bad breath.

Perfect White Black is Beverly Hills Formula's latest and most innovative product yet and is set to revolutionise tooth whitening toothpastes, most of which, until now, have been white.

The new toothpaste joins Beverly Hills Formula Perfect White and Perfect White Sensitive toothpastes, all designed to give make teeth whiter and brighter in just five minutes.

Beverly Hills Formula Perfect White and Perfect White Sensitive toothpastes are enriched with key ingredients such as advanced hydrated silica which offers high performance whitening enhancement, whilst the stain dissolvent agent pentasodium triphosphate prevents food particles from settling on your teeth.

Perfect White also provides a protective coating of tetrasodium pyrophosphate, an extra stain removal anti-tartar ingredient, and triclosan which kills plaque-forming bacteria. If you suffer from sensitive teeth, the Perfect White Sensitive offers you all the benefits of Perfect White but with the added assistance of potassium citrate, for immediate sensitivity relief.

Beverly Hills Formula has also been shown to be one of the least abrasive whitening toothpastes on the market compared to other leading brands.

http://beverlyhillsformula.com/

\title{
RECEIVE FREE SAMPLES AT THIS YEAR'S SHOWCASE
}

\section{Visit the team from GSK Consumer}

Healthcare on stand PO6 at this year's British Dental Industry Association (BDIA) Dental Showcase to find out about Sensodyne and Corsodyl products and to receive samples

Sensodyne Repair \& Protect toothpaste contains NovaMin, an innovative

\author{
desensitising agent which builds a robust. \\ reparative layer over and within dentine \\ tubules to provide clinically proven \\ sensitivity relief and help protect against \\ the pain of sensitive teeth. \\ Corsodyl Toothpaste contains a unique \\ $67 \%$ sodium bicarbonate and fluoride \\ formulation which provides effective
}

plaque removal even in hard-to-reach areas and helps to stop bleeding gums. Visit GSK Consumer Healthcare on stand P06 on 9-11 October 2014 at ExCeL London

CORSODYL and SENSODYNE are registered trademarks of the GSK group of companies.

If you would like to promote your products or services direct to the dental industry in BDJ Team, just give Steve Brown a call on 02078434724 or drop an email to stephen.brown@nature.com 